\title{
Ecological traps for large-scale invasive species control: predicting settling rules by recolonising American mink post-culling
}

Article

Accepted Version

Melero, Y., Cornulier, T., Oliver, M. K. and Lambin, X. (2018) Ecological traps for large-scale invasive species control: predicting settling rules by recolonising American mink postculling. Journal of Applied Ecology, 55 (4). pp. 1769-1779. ISSN 0021-8901 doi: https://doi.org/10.1111/1365-2664.13115 Available at https://centaur.reading.ac.uk/83094/

It is advisable to refer to the publisher's version if you intend to cite from the work. See Guidance on citing.

To link to this article DOI: http://dx.doi.org/10.1111/1365-2664.13115

Publisher: British Ecological Society

All outputs in CentAUR are protected by Intellectual Property Rights law, including copyright law. Copyright and IPR is retained by the creators or other copyright holders. Terms and conditions for use of this material are defined in the End User Agreement.

www.reading.ac.uk/centaur 
Central Archive at the University of Reading

Reading's research outputs online 
1 Ecological traps for large-scale invasive control: Predicting settling rules by

2 recolonising American mink post-culling.

3

4 Yolanda Melero ${ }^{1,2 *}$, Thomas Cornulier ${ }^{1}$, Matthew K. Oliver ${ }^{1}$ and Xavier Lambin ${ }^{1}$

$5 \quad{ }^{1}$ School of Biological Sciences, University of Aberdeen, Aberdeen AB24 2TZ, UK

$6 \quad{ }^{2}$ Current address: CREAF, Cerdanyola del Vallés 08193, Spain

7

$8 \quad$ *Correspondence author. E-mail: x.lambin@abdn.ac.uk. Phone: + 44(0)1224 273259.

9 Mailing address: ${ }^{1}$ School of Biological Sciences, University of Aberdeen, Aberdeen AB24

$10 \quad 2 \mathrm{TZ}, \mathrm{UK}$

11 Yolanda Melero: y.melero@creaf.uab.es; Thomas Cornulier: cornulier@abdn.ac.uk;

12 Matthew K Oliver: mattoliverecology@gmail.com.

13

14 Running title: Ecological traps: Predicting settling rules

15 Word count: 6997. Summary (275), main text (4509), acknowledgements (42),

16 references (1603), table and figure legends (480), authors contribution (41)

\section{Number of tables: 1}

18 Number of figures: 5

19

20 Summary

21 1. Management programs worldwide seeking to reduce the density of invasive species must

22 overcome compensatory processes, such as recolonisation by dispersers from non- or

23 partially-controlled areas. However, the scale and drivers of dispersal in such context are

24 poorly known.

25 2. We investigated the dispersal patterns of American mink reinvading $20,000 \mathrm{~km}^{2}$ of their

26 non-native range following a culling programme led by citizen conservationists. Using 
27 multinomial models, we estimated the contributions of density dependence, proxies for patch

28 quality and distance from the natal patch on mink settlement.

29 3. Seventy seven percent of mink dispersed and settled in non-natal patches. Dispersal

30 distances were large with settlement probabilities only reduced by half at $\sim 60 \mathrm{~km}$, and $20 \%$

31 of mink dispersing $>80 \mathrm{~km}$.

32 4. Females were more attracted to patches of high quality mostly found at low altitudes.

33 Males favoured patches with intermediate current densities and consistently high quality.

34 Synthesis and applications. Predicting post-culling recolonisation by a non-native mobile

35 carnivore over large spatial scale could was using information on relative densities obtained

36 during management interventions largely implemented by citizen conservationists. This was

37 made possible by a monitoring component designed to feed into the adaptive management

38 process implemented in this project. High mink mobility dictates management should take

39 place on very large spatial scales to minimise reinvasion from un-controlled areas. Both

40 males and females were attracted to patches that were previously consistently occupied,

41 providing a degree of predictability to patterns of recolonisation. Targeting control to patches

42 attractive to immigrant mink requires knowledge of current mink density. Creating so-called

43 ecological traps in the face of ongoing immigration from peripheral areas provides a

44 promising tool to effectively control mobile invasive species.

46 Keywords: invasive species, dispersal, settlement, compensation, immigration, adaptive

47 management, ecological traps

49 Introduction

50 Understanding the ecological processes governing invasive species population dynamics and

51 mitigating their threat to native ecosystems is a focus of much research (e.g. Simberloff et al.

52 2013, Hastings et al. 2005). Efforts to reverse the spread of invasive mammals have become

53 more rigorously designed and implemented, achieving eradications of e.g. rats, mice, cats and

54 rabbits on islands of increasingly large size (Bester et al. 2002; Barun et al. 2011; Kessler 
55 2011). Where eradication is not feasible, the management objective is suppressing numbers

56 to near-zero density or to densities sufficiently low to allow the recovery of affected native

57 species (Norbury et al. 2015); as with red foxes and feral cats in Australia, Moseby \& Hill

58 2011; stoats in New Zealand, Veale, Clout \& Gleeson 2011). However, management

59 interventions focused on control must contend with compensatory recolonisation through

60 dispersal from adjoining uncontrolled areas.

61 Reducing densities of invasive species by culling typically produces density

62 dependent compensatory responses in surviving individuals, such as increased fecundity and

63 survival (Boyce, Sinclair \& White 1999; Pöysä 2004; Melero, Robinson \& Lambin 2015).

64 Reduced competition for resources may also stimulate dispersal from adjoining high-density

65 areas towards culled low-density areas. If individuals are able to detect variations in resource

66 availability, both residents that have escaped culling as well as immigrants may settle in

67 productive low-density areas and partially or completely negate culling efforts through

68 reinvasion (e.g. Matthysen 2005; Lieury et al. 2015). While such dispersal patterns would

69 tend to accelerate the recovery of the culled population, they can be harnessed so as to create

70 ecological traps in attractive but vacant areas where targeted ongoing culling would

71 effectively prevent population recovery through immigration (Delibes, Ferreras \& Gaona

72 2001; Robinson et al. 2008; Lieury et al. 2015; e.g. Gervasi et al. 2015; Oliver et al. 2016).

73 Accordingly, understanding the drivers of dispersal, including settlement rules used by

74 dispersers at low density, may be central for optimising the management of invasive species

75 by spatially targeting control efforts (Glen, Pech \& Byrom 2013).

76 Most studies of individual dispersal decisions have hitherto focused on emigration

77 (Clobert et al. 2012; Altwegg et al. 2012; Furrer \& Pasinelli 2015; but see Turgeon \&

78 Kramer 2012; Glen, Pech \& Byrom 2013). The factors that determine settlement decisions

79 are comparatively poorly known, even for the best-studied model organisms. Theoretical

80 investigations predict that a disperser's settling decision should depend on its ability to access

81 information on the quality of potential patches (Ruxton \& Rohani 1999; Vuilleumier \&

82 Perrin 2006). This in turn may be influenced by the perceptual range and mobility of 
83 dispersers and by the properties of the landscapes through which they move (Miller et al.

84 2011; Hovestadt, Mitesser \& Poethke 2014). Most problematic predatory mammalian

85 invasive non-native species are highly mobile (e.g. red fox, cats, stoats, mink and mongoose;

86 Genovesi et al. 2012) and hence can acquire information about settlement opportunities over

87 large areas. A fundamental question is therefore: how do individuals make decisions in

88 relation to their settlement choices (Sutherland et al. 2013; Gilroy \& Lockwood 2016).

89 Habitat quality and conspecific density are known to influence the attractiveness of

90 potential settlement areas to dispersers (e.g. Turgeon \& Kramer 2012; Glen, Pech \& Byrom

91 2013). Therefore, the balance between quality and the positive and negative influences of

92 density (due to e.g. conspecific attraction and competition for resources, respectively) might

93 also shape individual decisions. Generally, relatively more individuals are expected to settle

94 in poor quality sites at high-density than in low density populations (e.g. Gunnarsson et al.

95 2005). Indeed, in harvested cougar populations (Puma concolor), dispersers settled

96 preferentially in high quality habitats where conspecific density was reduced by harvest

97 (Robinson et al. 2008; Wolfe et al. 2013) and their settlement probability declined with

98 distance from the location of birth (Morrison, Boyce \& Nielsen 2015). Performing studies at

99 sufficiently large scale relative to the large dispersal ability of predatory mammals is

100 particularly challenging (Glen, Pech \& Byrom 2013), such that, little is known about the

101 dispersal and settling rules they (Glen, Pech \& Byrom 2013; Oliver et al. 2016).

102 In order to provide the necessary understanding to optimally counter recolonisation

103 through immigration, we sought to describe how dispersal distance, density dependence and

104 patch quality affect settlement probability of the invasive American mink (Neovison vison).

105 Mink is a globally widespread invasive species and the focus of much long-term control

106 efforts (Bonesi \& Palazón 2007; Genovesi et al. 2012). They are solitary, territorial

107 carnivores inhabiting linear territories along watercourses. Mating occurs in February-March

108 in Scotland, when rutting males, but not females, abandon their territories, travelling tens of

109 kilometres in search of mating opportunities (Melero \& Palazón 2011; Melero, Robinson \&

110 Lambin 2015). Dispersal is thought to occur once, when juveniles of approximately 5 months 
111 old leave the maternal territory seeking a vacant territory in which they typically settle by the

112 end of the year (Gerell 1970; Dunstone 1993).

113 We used multinomial models to analyse how recolonising mink selected settlement

114 locations amongst available patches where their conspecifics had been removed by a large-

115 scale citizen conservationist-based, project seeking to suppress mink populations in their

116 invasive range in NE Scotland (Bryce et al. 2011). We predicted a negative influence of

117 distance from the natal patch on settling probability (Oliver et al. 2016) and that dispersers

118 would preferentially settle in patches of relatively high quality that host a moderate number

119 of conspecifics, reflecting the dual influences of mate attraction and competition for

120 resources.

121

122 Methods

\section{STUDY AREA}

124 The mink control program started in 2006 in the Cairngorms National Park $\left(57^{\circ} 0{ }^{\prime} \mathrm{N}, 3^{\circ}\right.$

$12530^{\prime}$ W, Fig. 1a) NE Scotland and gradually expanded spatially in a non-systematic manner,

126 reaching $\sim 20,000 \mathrm{~km}^{2}$ by 2012 (Bryce et al. 2011). This area covers an heterogeneous

127 landscape mixing highlands up to $1300 \mathrm{~m}$ altitude dominated by acidic grasslands and bogs

128 with mean coverage $36.7 \%$ and $25.4 \%$ at $25 \mathrm{~m}$-scale) and a coastal lowland plain partially

129 dominated by rough and improved grass (mean $8 \%$ and 30\%, ranges $0-100 \%$ ) respectively

130 (see Bryce et al. 2011) (Fig 1). The project area spanned 16 river catchments totalling 2,500

$131 \mathrm{~km}$ of waterway, subdivided into 21 sections (patches hereafter) reflecting project

132 management units where mink control and monitoring were instigated at the same time (see

133 Bryce et al. 2011; Melero, Robinson \& Lambin 2015). Patches had a mean waterway length

134 of $153 \mathrm{~km}$ (SD 26; Fig. 1a). The asynchrony in the inception of comprehensive control in

135 each river catchment led to a patchwork with different mink densities, each surrounded by

136 variable numbers of other patches not yet subjected to control and variably fuelling

137 recolonisation of adjacent patches. No mink were recorded or captured in one unit, so it was

138 excluded from analyses. 


\section{DATA COLLECTION}

141 Project activities were mostly undertaken by volunteers who detected, trapped and removed

142 mink, and were coordinated by three to four project officers. Mink were detected using mink

143 rafts (Reynolds, Short \& Leigh 2004) deployed at regular intervals along waterways. A trap

144 was placed on the raft following detection, and left in place for a few days or until a mink

145 was caught and humanely dispatched. Sustained culling led to density reductions of $50 \%$

146 after the first year of fully-comprehensive control, achieving overall density reductions of

$14780 \%$ after 6 years (Melero, Robinson \& Lambin 2015). The carcasses of $86 \%$ of 979 culled

148 mink were collected from ca. 400 volunteers for later dissection of which 387 were females,

149452 were males and 140 were of unknown sex (Fig. 1b). The carcasses of the remaining $14 \%$

150 mink were not retained. Mink sex was determined and a canine tooth and muscle tissue

151 samples were removed for age determination and molecular analyses, respectively. Mink age

152 was estimated through X-ray of canines (Helldin, 1997) and using tooth cementum analyses

153 for non-juveniles performed by Matson’s Laboratory LLC (Manhattan, USA).

154

155 CANDIDATE PREDICTORS OF SETTLEMENT DECISIONS

156 Dispersing mink are faced with a choice between multiple patches they could settle in. We

157 modelled the probability that an individual chooses a specific patch amongst all possible

158 candidates in relation to patch specific and individual-level covariates.

\section{CHOICE-SPECIFIC VARIABLES}

161 We were interested in understanding how the following environmental and population

162 covariates at the patch-level affected patch choice: patch quality (constant), natal dispersal

163 (individual specific) and conspecific density (time-varying).

165 Environmental covariates 
$16720,000 \mathrm{~km}^{2}$ was unachievable, so we used the data available in the control project to derive 168 proxies of patch quality. First, we assumed that the most attractive patches would be those 169 with consistently high occupancy. Thus we used as proxy of patch quality, $Q$, the maximum 170 proportional length of a patch occupied by settled adult mink for the 6 year duration of the 171 study (cumulative total $\mathrm{km}$ occupied/total patch length in $\mathrm{km}$ ) following the procedure 172 detailed in Melero, Robinson \& Lambin (2015).

173 Calculations of $Q$ did not exclude those mink focal to our inferences, which we

174 acknowledge may impose a degree of non-independence between the explanatory and 175 dependent variables. However, only $20 \%$ of the mink captures used to define $Q$ were focal 176 mink, such as their contribution in $Q$ was per patch was low. To overcome potential caveats 177 associated with using $Q$, we also used a set of habitat variables previously found to predict 178 mink occurrence in Scotland (Fraser et al. 2015) at $1 \mathrm{~km}$ buffer (reflecting mink home 179 ranges; Melero et al. 2008). These were mean altitude and proportion of improved grass, acid 180 grass, rough grass, and bog, mapped at $25 \mathrm{~m}$ resolution, derived from Land Cover Map 181 (LCM) 2007 data for the UK (Morton et al., 2011) using ArcGis 10.1 (ESRI, 2014) at $1 \mathrm{~km}^{2}$ 182 pixel. Because $Q$ and candidate habitat descriptors were likely to be correlated, we fitted two 183 distinct models to ensure interpretability. Model-1 included $Q$ and all population and 184 individual covariates described below but not the habitat covariates, whilst Model-2 included 185 all covariates except $Q$ (see below).

186 Approximate natal dispersal distances were taken as the distance between natal and 187 culling patches. This distance was measured as the Euclidean distance between the arithmetic 188 means of the capture locations of all mink culled in each patch (i.e. from the centroid of the 189 natal to that of settlement patch) as mink appear unconstrained by waterways in their 190 dispersal (Oliver et al. 2016). This reduced the error due to mink mobility within the patch

191 (i.e., capture location does not necessarily relate to the location of activity), but reduced the 192 resolution reported using exact locations (e.g. Oliver et al. 2016 Natal patch was inferred 193 using a combination of information on pedigrees (Appendix S1, Supporting Information), 
194 and dates and locations of capture and birth following Telfer et al. (2003). The natal patch

195 was deemed to be that of the capture location of an individual's mother. When the mother

196 was unknown, it was taken as the capture location of an individual's full- or maternal half-

197 siblings if siblings were captured prior to the seasonal initiation of natal dispersal (October).

198 Fathers and paternal half-siblings were not used because males roam widely during the rut

199 and their locations of capture poorly reflect the natal patch of their offspring (Dunstone,

200 1993). The settlement patch was taken to be the capture location of those individuals deemed

201 to be holding a territory at the time of capture (i.e. settled mink). Thus, we excluded those

202 mink likely to be transient (i.e. mink < seven months old, assuming all were born in June)

203 and rut males (i.e. male mink caught during the mating season, February-March).

204

205

Population density covariates

206 Due to the large scale of our study, it was unfeasible to estimate time-varying mink density.

207 Instead, we used relative density values taken as the ratio of the number of captured

208 territorial individuals in a calendar year relative to the maximum number of mink potentially

209 settling in that patch (using $Q$ as denominator). We did so in the knowledge that not all mink

210 present in a given year and location were trapped but under the assumption that the number

211 of mink caught was proportional to the number of mink present, and therefore that the

212 estimate would capture biologically relevant variation in density. Relative density was

213 calculated pooling males, females and mink of unknown sex as the later account for $14 \%$ of

214979 mink caught. Both relative density $(\mathrm{RD})$ and its quadratic term $\left(\mathrm{RD}^{2}\right)$ were included as

215 candidate explanatory covariates in the analyses to allow for positive and negative influences

216 of density.

218 INDIVIDUAL-SPECIFIC COVARIATES

219 The influence of patch-specific covariates on settlement decisions is likely to differ between

220 classes of individuals. Accordingly, we included sex as an individual-level covariate within

221 all patch-specific covariates in our analyses. Dispersal distances inferred from pedigree 
222 assignments are not error-free in partially sampled populations (Leonarduzzi et al. 2012;

223 Melero, Oliver \& Lambin 2017). Hence, when considering dispersal distance, we first

224 included the inferred relationship type (mother-offspring, full- or (maternal) half-siblings)

225 used to infer natal patch as an individual-level covariate. We expected that the most error-

226 laden assignments would see the greatest shrinkage of the effect of distance, with errors

227 increasing from mother-offspring, to full- and half-sibling (Melero, Oliver \& Lambin

228 2017). Relationships with the highest reliability (mother-offspring; Melero, Oliver \& Lambin

229 2017) were then used to test the sex-distance interaction.

230 Finally, following Vardakis et al. (2015), we included a 'home advantage' variable in

231 the models. This allows the probability of staying in the natal patch to be independent of the

232 distance-to-travel effect.

All continuous variables were standardised by subtracting the mean and dividing by

235 the standard deviation to assess the relative contribution of each variable to settlement

236 probability.

\section{MODELLING DISPERSAL DECISIONS}

239 Dispersal movement data have recently been analysed using multinomial discrete choice

240 models (multinomial regression models), where the probability of settling in a particular

241 patch is a function of patch- and individual-level covariates (Vardakis et al. 2015). We used

242 multinomial probit models to describe individuals' choice from a finite set of mutually

243 exclusive alternatives.

244 The models assume that an individual $i$ selects its preferred settlement patch from the

245 entire set of available patches $p=1, \ldots, P$. Relative preference by individual $i$ is modelled

246 through a $(P-1) \times 1$ latent variable vector $\Lambda_{i}$. The chosen patch is assumed to be the one

247 with the highest value of the latent variable:

$248 \quad Y_{i}\left(\Lambda_{i}\right)=\left\{\begin{array}{c}0 \text { if } \max \left(\Lambda_{i}\right)<0 \\ p \text { if } \max \left(\Lambda_{i}\right)=\Lambda_{\text {ip }}>0\end{array}\right.$, for $i=1, \ldots, N$ and $p=1, \ldots, P-1$ 
249 Where $Y_{i}$ is the index of the chosen patch and $Y_{i}=0$ is an arbitrarily chosen reference patch.

250 The latent variable vectors $\Lambda_{i}$ are defined as a function of $k$ covariates:

$$
\Lambda_{i}=X_{i} \beta+\varepsilon_{i}
$$

$252 X_{i}$ is a $(P-1) \times k$ matrix of choice-specific and individual-specific covariates (listed in the 253 previous section), and $\beta$ is a $k \times 1$ vector of regression coefficients. $\varepsilon_{i}$ is $(P-1) \times 1$

254 multivariate normal vector of errors $\varepsilon_{i} \sim N(0, \Sigma)$ where $\Sigma$ is a $(P-1) \times(P-1)$ positive-

255 definite matrix which allows for some redundancy between alternative choices (Ray 1973).

256 We made the simplifying assumption that our study area included all possible

257 alternatives, given the $20,000 \mathrm{~km}^{2}$ size of our study area, even though not all patches were

258 covered at the start of the project, such that some individuals may have died of natural cause

259 undetected after settling. The models were fitted in a Bayesian setting using a Markov Chain

260 Monte Carlo (MCMC) procedure, using package MNP in R 3.0.2 software (R Core Team

261 2016). We used the default non-informative priors (Gaussian with "infinite" variance) and

262 drew 1,050,000 MCMC Gibbs samples, discarding the first 50,000 and retained one iteration

263 in 100 for storage-saving purposes (for implementation see Appendix S2). We ran five

264 independent MCMC chains, starting from overdispersed values and diagnosed their

265 convergence with the Gelman-Rubin statistic (Table S1; Gelman \& Rubin 1992).

266 

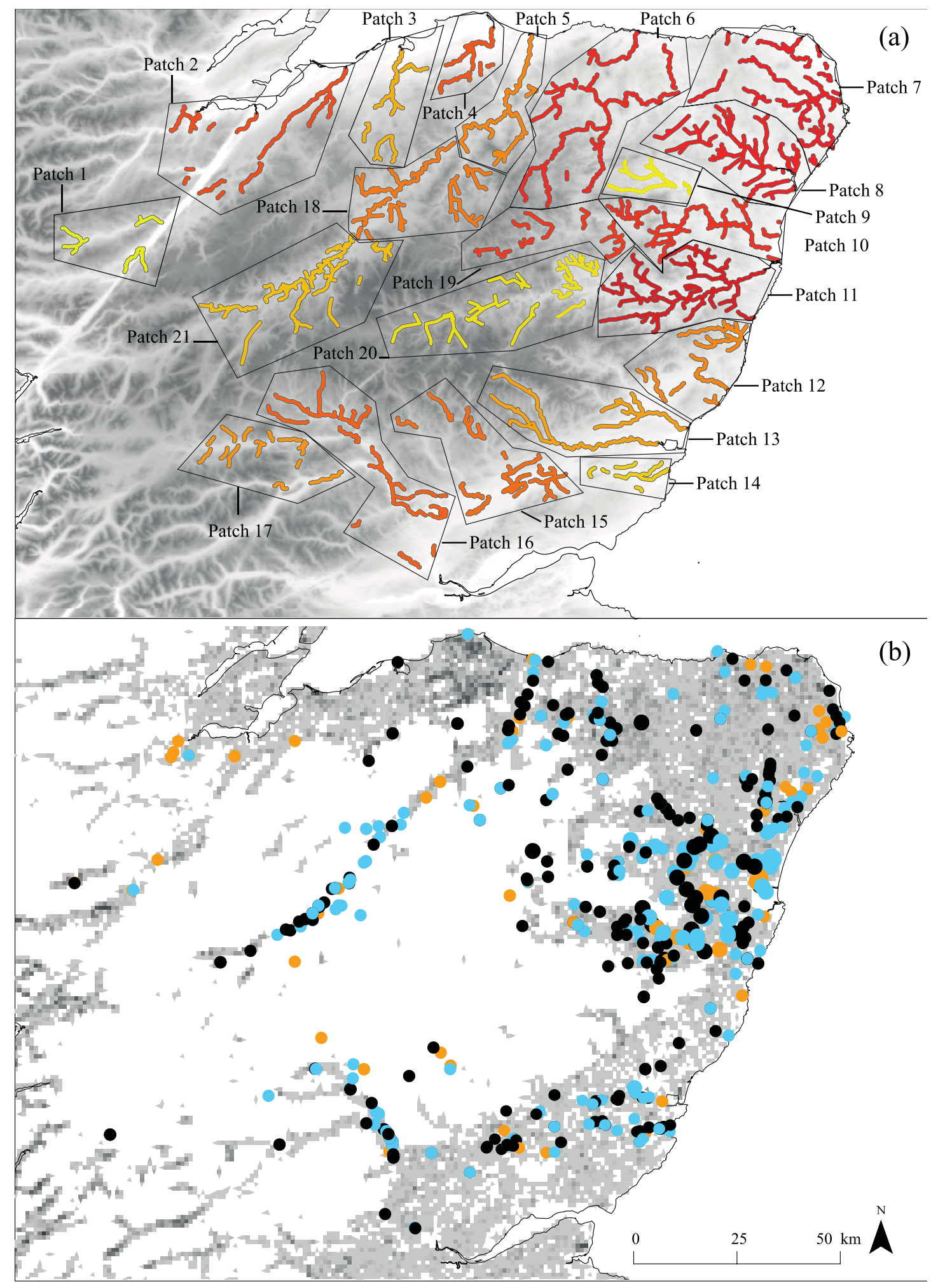

268 Figure 1. (a) The 21 patches coloured in yellow-to-red scale as per their gradient in quality $Q$

269 (1-41\% past use). The white-to-grey scale background relates to the gradient of altitude

270 (spanning 0-1300 m). (b) Settled female (blue circles, N=387), settled male (black circles; N 
$271=452$ ) and mink of unknown sex (orange circles, $\mathrm{N}=140$ ). The grey scale background

272 relates to the gradient of rough grass (1-100\%, white relates to zero rough grass).

273

$274 \quad$ Results

275 All mink contributed to estimating the population density covariates, but only 479 out of 839

276 mink with known sex were successfully assigned to a relative (mother or pre-dispersal

277 sibling) from which we could infer the natal location. Of these, $76.7 \%$ and $77 \%$ of adult

278 females and males, respectively, were caught as outside their natal patch (Fig. S1).

279 Mink settlement decisions were influenced by both environmental and population

280 covariates. Conspecific density $\left(\mathrm{RD}\right.$ and $\left.\mathrm{RD}^{2}\right)$ was a positive driver in both models, although

281 the strength of its effect was lower in Model-2 (Table 1). Male probability of settlement

282 increased with increasing conspecific density up to approximately $50 \% \mathrm{RD}$, but started to

283 decline when $\mathrm{RD}$ exceeded $\sim 60 \% \mathrm{RD}$, with no evidence of any effect at highest relative

284 densities (Fig. 2). The influence of density on female settlement was comparatively weak

285 (Fig. 2).

286 


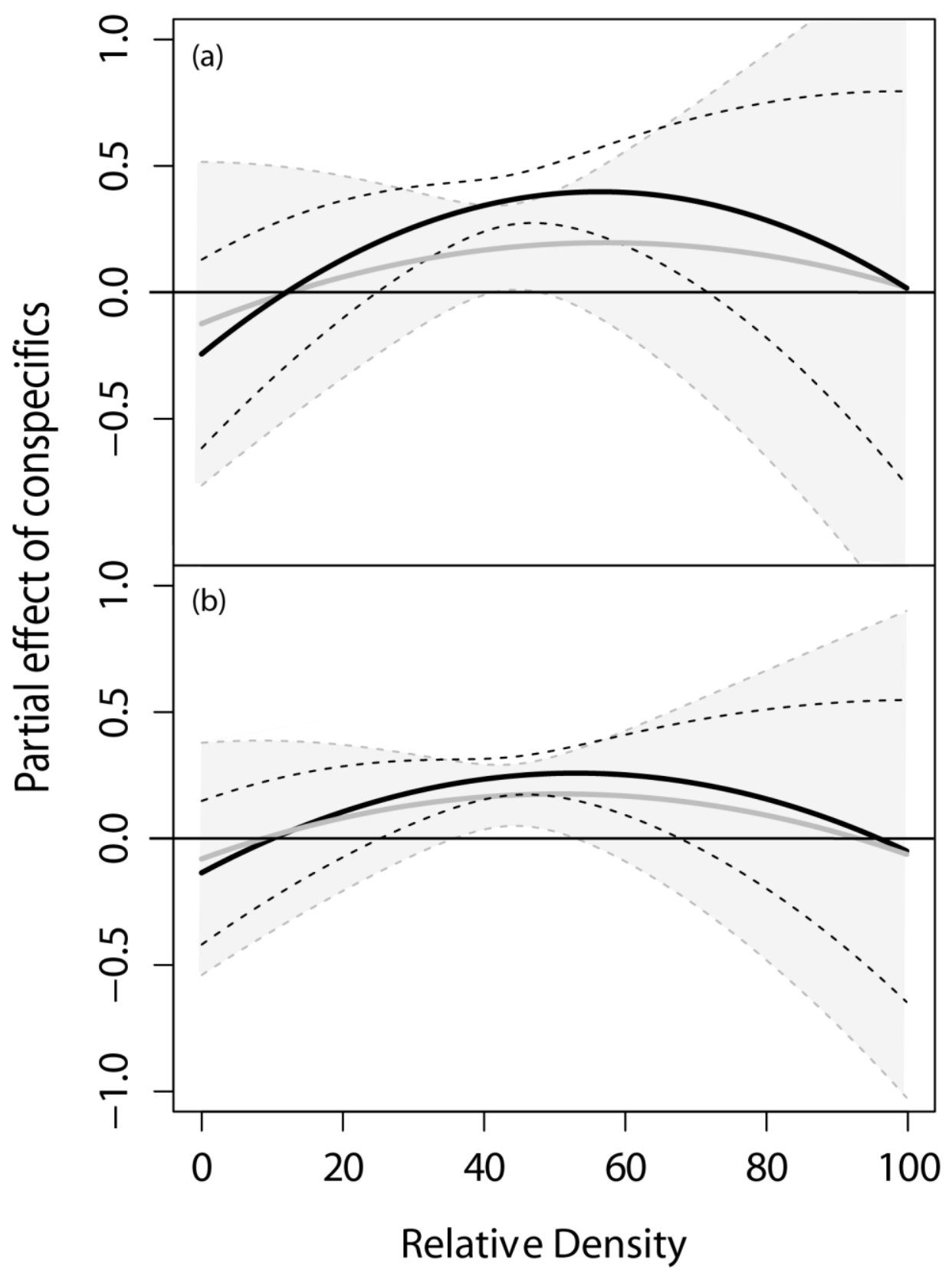

288 Figure 2. Estimated marginal effect of relative density (i.e., proxy of the saturation by 289 conspecifics) on mink settlement probability (i.e. the additive effect on the link scale of 290 relative density on the probability of choosing a patch) and 95\% credible intervals (dashed 291 lines) for (a) Model-1 (using occupancy as an indicator of patch quality) and (b) Model-2 292 (using habitat covariates as an indicators of patch quality), and for males (black lines) and 293 females (grey lines and shadows). Solid horizontal lines represented no effect $(y=0)$. 
295 Table 1. Posterior coefficient estimates for standardised patch-specific covariates (posterior 296 mean, standard deviation and 95\% credible intervals bounds). Covariates with the "female" 297 subscript (e.g. "RD Female") denote the difference between the effect of this covariate on 298 females compared to its effect on the reference level, in this case, males. " $\mathrm{D}_{\text {full sibling" and }}$ 299 "Dhalf sibling" are the difference between the effect of distance D for the reference level (D 300 inferred from mother-offspring relationship) and the effect of D with D inferred from full and 301 half sibling relationships respectively. $Q$ relates to patch quality and RD to relative density. 302 Bold indicates significant covariates.

\begin{tabular}{|c|c|c|c|c|c|c|c|c|}
\hline & \multicolumn{4}{|c|}{ (a) Model-1 } & \multicolumn{4}{|c|}{ (b) Model2 } \\
\hline & Estimate & $\mathrm{SD}$ & $2.5 \%$ & $97.5 \%$ & Estimate & SD & $2.5 \%$ & $97.5 \%$ \\
\hline $\mathrm{RD}$ & 0.86 & 0.17 & 0.54 & 1.20 & 0.60 & 0.13 & 0.35 & 0.87 \\
\hline $\mathrm{RD}_{\text {Female }}$ & -0.47 & 0.23 & -0.94 & -0.02 & -0.19 & 0.17 & -0.51 & 0.13 \\
\hline $\mathrm{RD}^{2}$ & -0.81 & 0.17 & -1.15 & -0.48 & -0.61 & 0.14 & -0.90 & -0.35 \\
\hline $\mathrm{RD}_{\text {Female }}^{2}$ & 0.46 & 0.24 & -0.01 & 0.93 & 0.17 & 0.17 & -0.15 & 0.51 \\
\hline Q & 0.45 & 0.03 & 0.40 & 0.51 & & & & \\
\hline $\mathrm{Q}_{\text {Female }}$ & 0.03 & 0.03 & -0.03 & 0.08 & & & & \\
\hline $\mathrm{D}$ & -0.39 & 0.05 & -0.51 & -0.29 & -0.31 & 0.05 & -0.42 & -0.22 \\
\hline $\mathrm{D}_{\text {full-siblings }}$ & 0.14 & 0.08 & -0.02 & 0.29 & 0.14 & 0.07 & 0.01 & 0.27 \\
\hline$D_{\text {half-siblings }}$ & 0.17 & 0.06 & 0.06 & 0.28 & 0.15 & 0.05 & 0.06 & 0.25 \\
\hline Home Adv & -0.18 & 0.07 & -0.32 & -0.04 & 0.07 & 0.06 & -0.05 & 0.19 \\
\hline Altitude & & & & & -0.26 & 0.16 & -0.61 & -0.01 \\
\hline Altitude $_{\text {Female }}$ & & & & & -0.10 & 0.05 & -0.20 & -0.02 \\
\hline Rough & & & & & -0.37 & 0.20 & -0.80 & -0.10 \\
\hline Rough Female $_{\text {F }}$ & & & & & 0.09 & 0.07 & -0.03 & 0.22 \\
\hline Bog & & & & & 0.05 & 0.07 & -0.05 & 0.21 \\
\hline Bog ${ }_{\text {Female }}$ & & & & & 0.02 & 0.03 & -0.04 & 0.08 \\
\hline
\end{tabular}


In both models, patch quality positively influenced mink settlement probability.

306 Settlement by both sexes strongly increased similarly with $Q$ (Model-1, Fig. 3a). Mink

307 settlement decisions followed a distinct spatial pattern since patches with highest $Q\left(3^{\text {rd }}\right.$

308 quartile $Q=19 \%$, range 1-41; Fig. S2) were located in the coastal plain and along valleys

309 floors. All patches had some coverage of rough grass (range 1-25\%) but mink were attracted

310 to those with lower than average cover and lower altitudes (both at $1 \mathrm{~km}$-radius-scale), with

311 lower altitude patches being more preferred by females relative to males (Table 1b, Fig. 3b-c).

312 Other covariates either did not provide further explanation of habitat quality (Table 1 - Model

313 2) or were correlated with covariates already present in the model (Fig. S3).

314
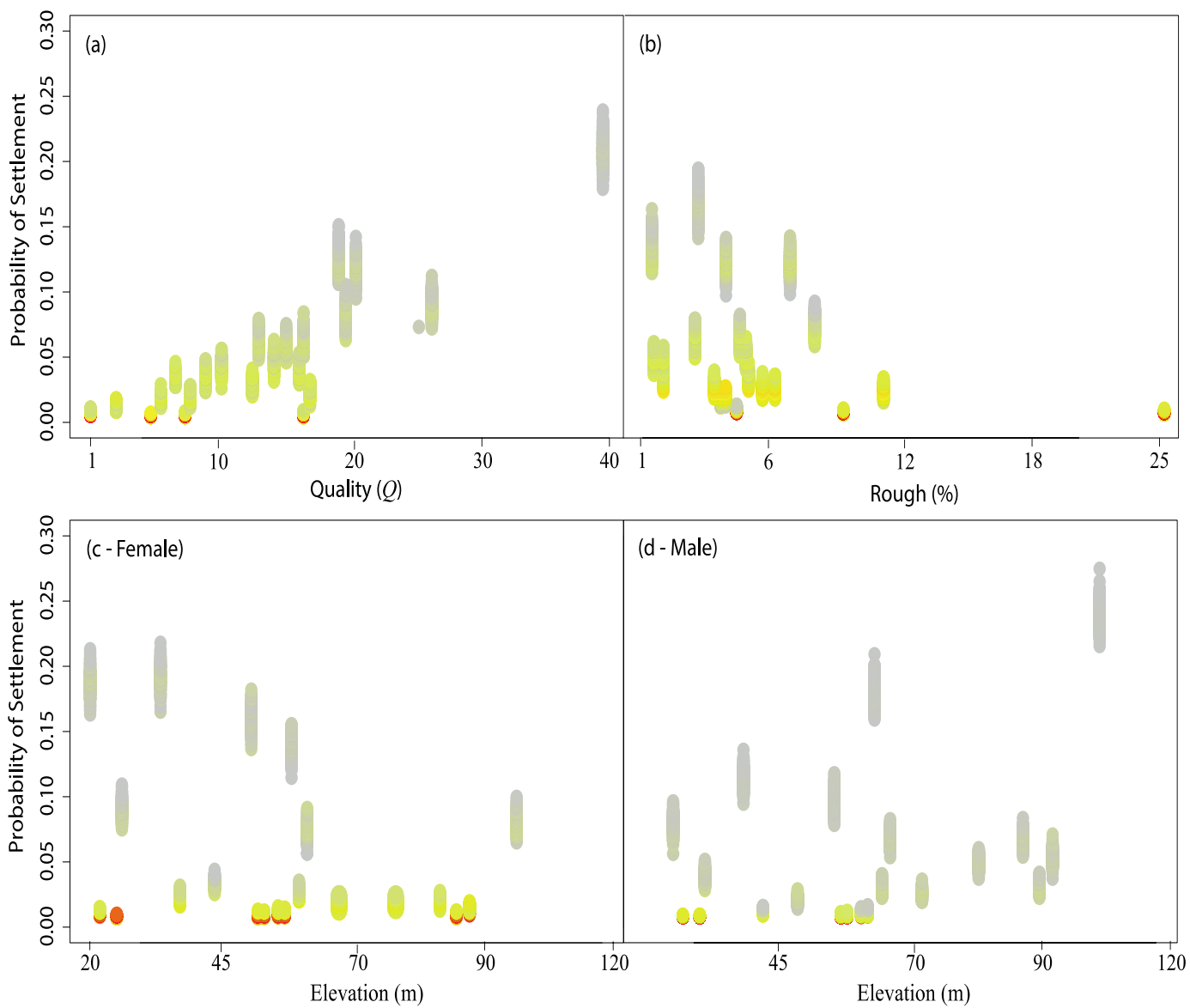

316 Figure 3. Partial predicted settlement probability for each mink and for each patch (i.e. each

317 of the 479 mink is confronted with a choice of 21 potential patches, giving a total of 9009

318 probabilities), represented in relation to the patch variables (a) $Q$, (b) percentage of rough 
319 grass, (c) altitude for females and (d) altitude for males. A gradient of colour has been linked

320 to the density of predicted values (low to high: grey-to-yellow-orange-red). Predictions are

321 based on holding all other covariates at their mean value.

322

323 Mink settlement probability declined with the distance from the natal patch in both

324 models and for all three types of kin relationships used to infer natal location (mother-

325 offspring, full- and half-siblings). The estimated negative slope of the relationship with

326 distance was reduced by $\approx 33 \%$, but not nullified, with assignment uncertainty levels, from

327 mother-offspring to full- and half-siblings (Table 1, Fig. 4a). Consistently, estimated

328 distances between centroids of natal and capture patches (Fig. S4) were longer when using

329 half-siblings (mean 26.31, 3rd quartile $58 \mathrm{~km}, \mathrm{~N}=324$ ) and full-siblings (mean 25.44, 3rd

330 quartile $55 \mathrm{~km}, \mathrm{~N}=44$ ) than when using mothers (mean $19.22 \mathrm{~km}, 3 \mathrm{rd}$ quartile $40 \mathrm{~km}, \mathrm{~N}=$

331 112).

332 Considering only mother-offspring relationships, distance between patches had a

333 similarly negative effect for both sexes (Fig. 4b, Fig. S5), reducing settlement probabilities to

334 half (from approximately 0.20 to $<0.10$ ) when patches were $>60 \mathrm{~km}$ distant from the natal

335 patch in both models and with $20 \%$ of males dispersing $>80 \mathrm{~km}$ (Fig. 5). The significant

336 effect of home advantage in Model-1 indicated that the probability of settling in the natal

337 patch was less than predicted solely using the distance effect at distance zero; Model-2 did

338 not capture this effect (Table 1).

339 


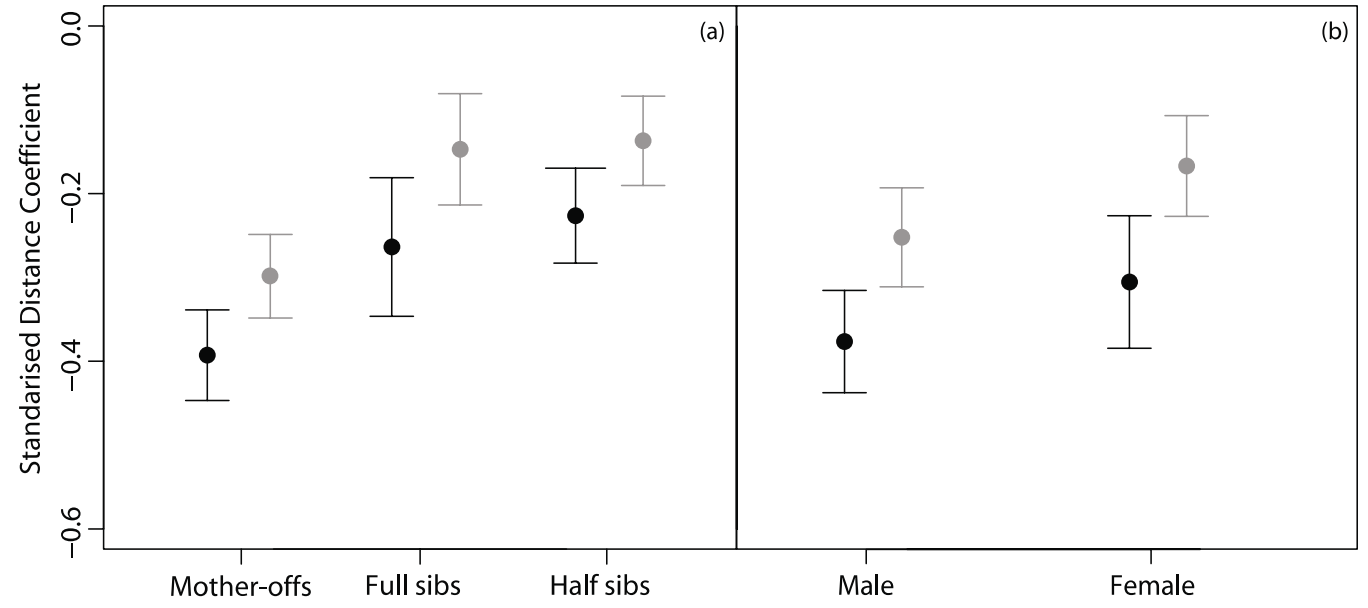

341 Figure 4. Estimated effect of the standardised distance from the natal patch on mink

342 settlement probability in relation in relation to (a) the relationship type and (b) sex using only

343 mother-offspring relationship for Model-1 (in black) and Model-2 (in grey). 


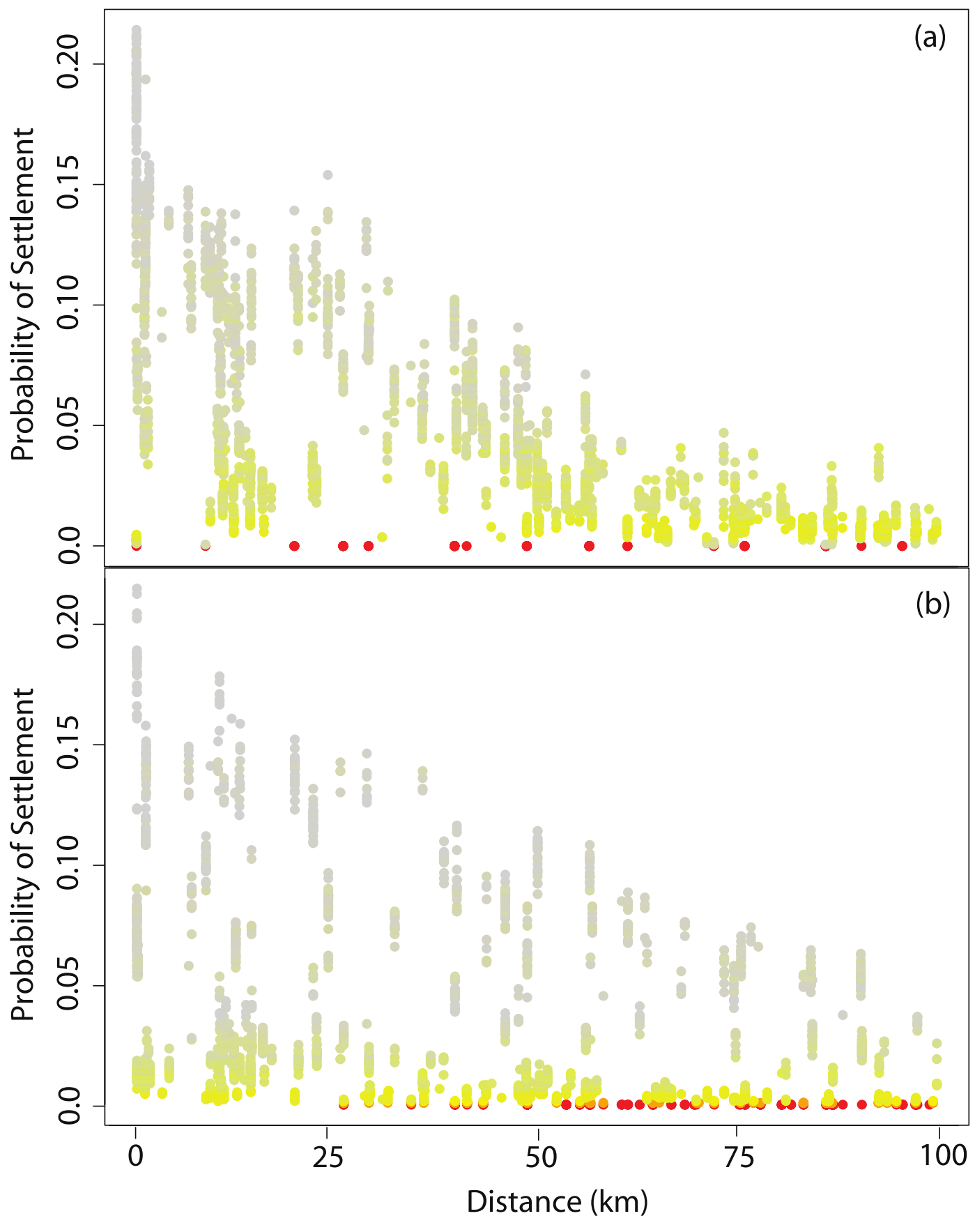

346 Figure 5. Partial predicted settlement probability for each mink and for each patch (i.e. each

347 of the 112 mink using only mother-offspring relationship is confronted with a choice of 21

348 potential patches, giving a total of 2352 probabilities), represented in relation to the distance

349 from the capture to the natal patch for (a) Model-1 and (b) Model-2. A gradient of colour has

350 been linked to the increasing frequency of predicted values (grey-to-yellow-orange-red).

351 Predictions are based on fixing all other covariates values at their mean. Predictions at

352 distance zero include a "home advantage" effect. 


\section{Discussion}

355 We used discrete choice models similar to Vardakis et al. (2015) for considering dispersal as 356 a choice process whereby individuals' decisions are ruled by the characteristics of the chosen 357 patch and of alternative choices. Using this relatively novel methodological approach, and

358 utilising dispersal data from mink recolonising a large area repeatedly depleted of 359 conspecifics by culling implemented by citizen conservationists, we provided evidence of

360 both density dependence and habitat quality affecting mink settlement decisions. Mink

361 selected high quality patches to settle in. Probability of settlement decreased with distance

362 from natal areas in a similar way for female and male mink but the distances reached were

363 long (mean $19 \mathrm{~km}$, max $100 \mathrm{~km}$ ), therefore not constituting a strong limitation. Our findings

364 indicate that large-scale mink control could be optimized by turning preferential settlement 365 areas in ecological traps.

\section{Dispersal distances and mink settlement}

368 The precision of natal dispersal distances estimates using inferred pedigrees depends 369 largely on the type of kinship relationship between mother and descendants (Melero, Oliver 370 \& Lambin 2017). We pragmatically ensured that our inferences are robust by accounting for 371 the influence of relationship type on the estimated effect of distance in the models. Not all 372 dispersers were detected and some mink immigrated and emigrated from our study area.

373 While these issues introduce a negative bias in estimations of dispersal distance in all studies 374 (Koenig, Van Vuren \& Hooge 1996), their impact was likely minimal owing to the 375 exceptionally large size of the study area and the fact that it was bounded over roughly $75 \%$ 376 of its periphery by the North Sea and the semi-permeable Cairngorms Mountains (Zalewski et al. 2009; Fraser et al. 2013). Re-invading mink of both sexes may have dispersed long 378 distances. Both mean $(19 \mathrm{~km})$ and maximum $(100 \mathrm{~km})$ dispersal distances are well in excess 379 of values predicted for carnivorous mammals of the size of mink (Sutherland et al. 2000) and 380 may have contributed to mink's success as an invasive species. Long-range dispersal by mink 
381 and other mobile invasive species dictates that vast areas should be monitored and removal

382 after an initial knock down phase to prevent re-establishment of a breeding population (e.g.

383 Oliver et al 2016; Lieury et al. 2015). Given the range of natal dispersal in mink, the resource

384 expenditure required would be unmanageable without some way of targeting monitoring

385 based on habitat selection.

386

387

Environmental quality and mink settlement

388 We evaluated two sets of candidate proxies for patch quality, giving pragmatic consideration

389 to the challenges of characterising $2,500 \mathrm{~km}$ of waterways. Both indices similarly had a

390 positive influence on the settlement decisions of male and female mink. This provides scope

391 for targeting monitoring to intercept and removing dispersers settling in areas turned into

392 ecological traps through culling (Delibes, Gaona \& Ferreras 2001; Delibes, Ferreras \& Gaona

393 2001).

394 The proxies of quality in Model-2 were remotely-sensed properties of the riparian

395 habitat. Unlike $Q$, they have the benefits of being available from the outset of any control

396 project or in any future expansion area. Consistent with female mammals being constrained

397 by the energetic demands of lactation, they indicated that female mink settled preferentially

398 in river sections located in the fertile lowland plain of the North-East portion of the project

399 area where arable farming is the dominant land use. The level of discrimination these proxies

400 provided was however limited, leaving $1,500 \mathrm{~km}$ of river with high quality scores, hence with

401 high priority for ongoing monitoring.

402 The second proxy, the consistency of patch use as defined by mink occupancy $(Q)$

403 was a good predictor of settlement consistent with inference from remote-sensed covariates.

404 It was the main factor predicting female mink settlement, with greater influence than distance

405 to the natal patch according to standardised regression coefficients. High quality patches

406 were mostly at low altitudes $\left(Q_{\text {lowlands }}\right.$ mean $=22.4, \mathrm{SD}_{\text {lowlands }}=10.1 ; Q_{\text {highlands }}$ mean $=8.8$,

$407 \mathrm{SD}_{\text {highlands }}=4.8$; Fig. S2) but not all lowland patches had high $Q$ values. Unlike remotely- 
sensed habitat proxies, $Q$ is derived from the management process and relies on mink

409 captures gradually accumulating.

$410 \quad$ Using $Q$ as proxy of patch quality as perceived by mink themselves to predict

411 settlement by immigrants and spatially prioritise management is a technique broadly

412 applicable to other species, even where detectability of settlers is $<100 \%$. It can be

413 particularly useful when measures of resources (e.g. food, shelter) are not attainable. Indeed

414 past occupancy is widely used as a proxy of quality where gradients of quality are steep, as in

415 metapopulation studies (Hanski \& Gilpin 1991; Johnson 2007).

\section{Density dependence and mink settlement}

418 Our metric of density was a time-varying relative estimate based on the number of mink 419 culled reported by volunteers. As the ratio of the number of occupied inferred territories per 420 patch in a calendar year relative to the maximum potential number of mink settling in that 421 patch, it is as a pragmatic measure of saturation relative to a notional carrying capacity.

422 Averaged annual relative patch density ranged from 6-90.4\%; median 20\%, overall range 0-

$423100 \%)$. There was evidence of non-linear effect of conspecific density (RD + RD ${ }^{2}$ effects)

424 with highest probability of settlement at intermediate densities; the effect being stronger for

425 male than for female. This density dependence supports the hypothesis of a trade-off between 426 the benefits of the presence of conspecifics, which may inform prospective immigrants about 427 patch quality and on the presence of females, and the costs of competition.

428 Detecting the dual influences of quality patches and conspecific density on

429 settlement probability was facilitated by the reduction in mink population density through

430 culling. Indeed density dependence in saturated conditions in the early stages of the project

431 likely contributed to some female mink settling in low quality patches in the upland reaches

432 of the river catchments (Aars et al. 2001; Bryce et al. 2011). Our analyses imply that mink

433 settled preferentially in the more productive lowland patches as relative densities decreased,

434 and adds to the evidence of compensatory immigration that is known to occur in other

435 controlled mammalian species (e.g. Loveridge et al. 2007; Lieury et al. 2015). 
Our results exemplify that, despite the unavoidable incomplete reporting and associated loss of information, engaging citizen-scientists in a conservation project makes it feasible to carry out management and collect data at an exceptionally large spatial scale while learning about key ecological processes.

443 eradication, identifying and focussing control effort on attractive areas is an effective option

444 for preventing reinvasion of an area following an initial knock down of the population. These

445 attractive areas where individuals are more likely to settle, can be used as ecological traps by

446 managers (Delibes, Ferreras \& Gaona 2001) by enhancing trapping effort via e.g. higher

447 volunteer deployment and renewal of rafts. These attractive areas are not of high

448 conservation value; which will mandate interception of mink before arrival. The promise of

449 increasing efficiency resulting from an adaptive management process should contribute to

450 reducing the vulnerability of invasive non-native species management efforts to fluctuations

451 in funding, which, in the UK, typically consist of discrete projects of 3-4 years duration in

452 lieu of long term strategic funding.

453 Remotely-sensed habitat variables identified clear gradients of attractiveness to

454 prospective immigrants but were not sufficiently descriptive to efficiently target long term

455 monitoring aimed at thwarting recolonisation of very large areas. A better characterization of

456 habitat variables defining attractiveness of river section within the productive lowlands

457 would be beneficial and applicable in newly controlled areas where mink resettlement

458 information is lacking. Variation in patch quality gathered from historical settlement

459 decisions by previous individuals can help ranking the attractiveness of potential settling

460 areas and more sharply focus monitoring and removal effort. The approach of relying on

461 habitat selection to spatially focus invasive control is however not without risk, as it relies on

462 statistically defined settling rules being faithfully used by all individuals. As such, it may not

463 be suited to eradication attempts, where it is crucial to remove all individuals. In an ongoing 
464 control program, evidence of variation in patch quality will become increasingly valuable to

465 refine knowledge of the location of potential attractive areas that can be used as ecological

466 traps as capture of immigrants accumulate and the predictive power of models improve.

467 Despite patches being large in our study due to historical management and sample size

468 limitations, the effects of the covariates were clear. Their scale, while ideally refined over

469 time as data accumulate, is nevertheless suitable for targeting control or volunteer staff

470 deployment to those portions of the overall project area most attractive to the immigrants and

471 suppress reinvasion.

472 A corollary is that while proxies of quality can be used to predict settlement, accurate

473 prediction of patch relative attractiveness to prospective immigrants at a given time ideally

474 requires knowledge of current density, or an appropriate proxy thereof. Supporting the

475 approach of spatiotemporal predictions for management (e.g. Baker 2017).

476

477 Authors' Contributions

478 Y.M and XL conceived the study, all authors interpreted the results and wrote the manuscript.

479 Y.M. performed the genetic analyses and estimated dispersal distance with M.K.O, and the

480 statistical analysis with T.C. X.L. supervised the research and management project.

482 Acknowledgments

483 Y. M. was funded by Marie Curie FP7-PEOPLE-2011-IEF 300288-Project Depensation, XL

484 and MO by NERC Grant NE/J01396X/1. We thank the Scottish Mink Initiative, staff,

485 funders including Scottish Natural Heritage and the People's Trust for Endangered Species,

486 all volunteers and the two reviewers.

487

488 Data Accessibility

489 Data of the culled American mink in NE Scotland (ID), their settlement choice and the

490 related covariates formatted for the multinomial model will be archived in Dryad. 
493 Aars, J., Lambin, X., Denny, R. \& Griffin, A.C. (2001) Water vole in the Scottish uplands:

494 distribution patterns of disturbed and pristine populations ahead and behind the

495 American mink invasion front. Animal Conservation, 4, 187-194.

496 Altwegg, R., Collingham, Y.C., Erni, B. \& Huntley, B. (2012) Density-dependent dispersal 497 and the speed of range expansions. Diversity and Distributions, 19, 60-68.

498 Baker, C.M. (2017) Target the Source: Optimal Spatiotemporal Resource Allocation for 499 Invasive Species Control. Conservation Letters, 10, 41-48.

500 Barun, A., Hanson, C.C., Campbell, K.J. \& Simberloff1, D. (2011) A review of small Indian 501 mongoose management and eradications on islands. Island invasives: eradication and 502 management (eds C.R. Veitch, M.N. Clout, \& D.R. Towns), pp. 17-25. UICN, Gland, Switzerland.

Bester, M.N., Bloomer, J.P., Van Aarde, R.J., Erasmus, B.H., Van Rensburg, P.J.J., Skinner,

Bonesi, L. \& Palazón, S. (2007) The American mink in Europe: Status, impacts, and control. J.D., Howell, P.G. \& Naude, T.W. (2002) A review of the successful eradication of

Boyce, M.S., Sinclair, A.R.E. \& White, G.C. (1999) Seasonal Compensation of Predation feral cats from sub-Antarctic Marion Island, Southern Indian Ocean. South African Journal of Wildlife Research, 32, 65-73. and Harvesting Seasonal compensation of predation and harvesting. Oikos, 87, 419-426.

Bryce, R., Oliver, M.K., Davies, L., Gray, H., Urquhart, J. \& Lambin, X. (2011) Turning back the tide of American mink invasion at an unprecedented scale through community

515 Clobert, J., Baguette, M., Benton, T.G. \& Bullock, J.M. (2012) Dispersal Ecology and 516 Evolution (eds J. Clobert, M. Baguette, T.G. Benton, \& J.M. Bullock). Oxford 
518 Delibes, M., Ferreras, P. \& Gaona, P. (2001) Attractive sinks, or how individual behavioural 519 decisions determine source-sink dynamics. Ecology Letters, 4, 401-403.

520 Delibes, M., Gaona, P. \& Ferreras, P. (2001) Effects of an attractive sink leading into 521 maladaptive habitat selection. American Naturalist, 158, 277-285.

522 Dunstone, N. (1993) The Mink. T and A D Poyserd Ltd, London.

523 Epanchin-Niell, R.S. \& Wilen, J.E. (2012) Optimal spatial control of biological invasions. $524 \quad$ Journal of Environmental Economics and Management, 63, 260-270.

525 Fraser, E.J., Lambin, X., Travis, J.M.J., Harrington, L.A., Palmer, S.C.F., Bocedi, G. \& 526 Macdonald, D.W. (2015) Range expansion of an invasive species through a 527 heterogeneous landscape: the case of American mink in Scotland. Diversity and 528 Distributions, 21, 888-900.

529 Fraser, E.J., Macdonald, D.W., Oliver, M.K., Piertney, S. \& Lambin, X. (2013) Using 530 population genetic structure of an invasive mammal to target control efforts - An example of the American mink in Scotland. Biological Conservation, 167, 35-42.

532 Furrer, R.D. \& Pasinelli, G. (2015) Empirical evidence for source-sink populations: a review on occurrence, assessments and implications. Biological Reviews of the Cambridge

Gelman, A. \& Rubin, D.B. (1992) Inference from Iterative Simulation Using Multiple Philosophical Society, onlline first.

Genovesi, P., Carnevali, L., Alonzi, A. \& Scalera, R. (2012) Alien mammals in Europe: updated numbers and trends, and assessment of the effects on biodiversity. Integrative Zoology, 7, 247-253.

540 Gerell, R. (1970) Home Ranges and Movements of the Mink Mustela vison Shreber in $541 \quad$ Southern Sweden. Oikos, 21, 160-173. 
542 Gervasi, V., Brøseth, H., Nilsen, E.B., Ellegren, H., Flagstad, Ø. \& Linnell, J.D.C. (2015)

543 Compensatory immigration counteracts contrasting conservation strategies of

544 wolverines (Gulo gulo) within Scandinavia. Biological Conservation, 191, 632-639.

545 Gilroy, J.J. \& Lockwood, J.L. (2016) Simple settlement decisions explain common dispersal 546 patterns in territorial species. Journal of Animal Ecology, 85, 1182-1190.

547 Glen, A.S., Pech, R.P. \& Byrom, A.E. (2013) Connectivity and invasive species

548 management: towards an integrated landscape approach. Biological Invasions, 15,

$549 \quad 2127-2138$.

550 Gunnarsson, T.G., Gill, J.A., Petersen, A., Appleton, G.F. \& Sutherland, W.J. (2005) A

551 double buffer effect in a migratory shorebird population. Journal of Animal Ecology, 74,

$552965-971$.

553 Hanski, I. \& Gilpin, M. (1991) Metapopulation dynamics: brief history and conceptual 554 domain. Biological Journal of the Linnean Society, 42, 3-16.

555 Hastings, A., Cuddington, K., Davies, K.F., Dugaw, C.J., Elmendorf, S., Freestone, A., ...

556 Thomson, D. (2005) The spatial spread of invasions: new developments in theory and 557 evidence. Ecology Letters, 8, 91-101.

558 Hovestadt, T., Mitesser, O. \& Poethke, H.-J. (2014) Gender-specific emigration decisions 559 sensitive to local male and female density. The American naturalist, 184, 38-51.

560 Johnson, M.D. (2007) Measuring habitat quality: a review. The Condor, 109, 489.

561 Kessler, C. (2011) Invasive species removal and ecosystem recovery in the Mariana Islands;

562 challenges and outcomes on Sarigan and Anatahan. Island invasives: eradication and

563 management. Proceedings of the International Conference on Island Invasives (eds C.R.

564 Veitch, M.N. Clout, \& D.R. Towns), pp. 320-324. IUCN, Gland, Switzerland.

565 Koenig, W.D., Van Vuren, D. \& Hooge, P.N. (1996) Detectability, philopatry, and the

566 distribution of dispersal distances in vertebrates. Trends in Ecology \& Evolution, 11, 
568 Leonarduzzi, C., Leonardi, S., Menozzi, P. \& Piotti, A. (2012) Towards an optimal sampling 569 effort for paternity analysis in forest trees: what do the raw numbers tell us? iForest $570 \quad$ Biogeosciences and Forestry, 5, 18-25.

571 Lieury, N., Ruette, S., Devillard, S., Albaret, M., Drouyer, F., Baudoux, B. \& Millon, A. 572 (2015) Compensatory immigration challenges predator control: An experimental 573 evidence-based approach improves management. The Journal of Wildife Management, $574 \quad 79,425-434$.

575 Loveridge, A.J., Searle, A.W., Murindagomo, F. \& Macdonald, D.W. (2007) The impact of 576 sport-hunting on the population dynamics of an African lion population in a protected $577 \quad$ area. Biological Conservation, 134, 548-558.

578 Matthysen, E. (2005) Density-dependent dispersal in birds and mammals. Ecography, 28, $579 \quad 403-416$.

580 Melero, Y., Oliver, M.K. \& Lambin, X. (2017) Relationship type affects the reliability of 581 dispersal distance estimated using pedigree inferences in partially sampled populations:

Melero, Y. \& Palazón, S. (2011) Visón americano--Neovison vison (Schreber, 1777). In: En: preferences of the invasive American mink (Mustela vison) in a Mediterranean area. partially compensates culling efforts of invasive non-native American mink. Biological Invasions, 17, 2645-2657.

591 Miller, T.E.X., Shaw, A.K., Inouye, B.D. \& Neubert, M.G. (2011) Sex-biased dispersal and 

the speed of two-sex invasions. The American Naturalist, 177, 549-61.

593 Morrison, C.D., Boyce, M.S. \& Nielsen, S.E. (2015) Space-use, movement and dispersal of $594 \quad$ sub-adult cougars in a geographically isolated population. PeerJ, 3, e1118.

595 Moseby, K.E. \& Hill, B.B.M. (2011) The use of poison baits to control feral cats and red 596 foxes in arid South Australia. Wildlife Research, 38, 338-349.

597 Norbury, G.L., Pech, R.P., Byrom, A.E. \& Innes, J. (2015) Density-impact functions for 598 terrestrial vertebrate pests and indigenous biota: Guidelines for conservation managers. 599 Biological Conservation, 191, 409-420.

600 Oliver, M.K., Piertney, S.B., Zalewski, A., Melero, Y.\& Lambin, X. (2016) The 601 compensatory potential of increased immigration following intensive American mink 602 population control is diluted by male-biased dispersal. Biological Invasions, 18, 3047$603 \quad 3061$.

604 Pöysä, H. (2004) Ecological basis of sustainable harvesting: is the prevailing paradigm of 605 compensatory mortality still valid? Oikos, 104, 612-615.

606 R Core Team. (2016) R: A Language and Environment for Statistical Computing.

607 Ray, P. (1973) Independence of Irrelevant Alternatives. Econometrica, 41, 987.

608 Reynolds, J.C., Short, M.J. \& Leigh, R.J. (2004) Development of population control 609 strategies for mink Mustela vison, using floating rafts as monitors and trap sites. 610 Biological Conservation, 120, 533-543.

611 Robinson, H.S., Wielgus, R.B., Cooley, H.S. \& Cooley, S.W. (2008) Sink populations in 612 carnivore management: cougar demography and inmigration in a huntd population. 613 Ecological Applications, 18, 1028-1037.

614 Roy, J., Yannic, G., Côté, S.D. \& Bernatchez, L. (2012) Negative density-dependent 615 dispersal in the American black bear (Ursus americanus) revealed by noninvasive 616 sampling and genotyping. Ecology and Evolution, 2, 525-537. 
617 Ruxton, G.D. \& Rohani, P. (1999) Fitness-dependent dispersal in metapopulations and its

618 consequences for persistence and synchrony. Journal of Animal Ecology, 68, 530-539.

619 Simberloff, D., Martin, J.L., Genovesi, P., Maris, V., Wardle, D.A., Aronson, J., ... Vilà, M.

620 (2013) Impacts of biological invasions: what's what and the way forward. Trends in

$621 \quad$ Ecology \& Evolution, 28, 58-66.

622 Sutherland, W.J., Freckleton, R.P., Godfray, H.C.J., Beissinger, S.R., Benton, T., Cameron,

623 D.D., ... Wiegand, T. (2013) Identification of 100 fundamental ecological questions ed

624 D. Gibson. Journal of Ecology, 101, 58-67.

625 Sutherland, G.D., Harestad, A.S., Price, K. \& Lertzman, K.P. (2000) Scaling of natal

626 dispersal distances in terrestrial birds and mammals. Ecology and Society, 4.

627 Telfer, S., Piertney, S.B., Dallas, J.F., Stewart, W.A., Marshall, F., Gow, J.L. \& Lambin, X.

628 (2003) Parentage assignment detects frequent and large-scale dispersal in water voles.

$629 \quad$ Molecular Ecology, 12, 1939-1949.

630 Turgeon, K. \& Kramer, D.L. (2012) Compensatory immigration depends on adjacent

631 population size and habitat quality but not on landscape connectivity. Journal of Animal

$632 \quad$ Ecology, 81, 1161-70.

633 Vardakis, M., Goos, P., Adriaensen, F. \& Matthysen, E. (2015) Discrete choice modelling of 634 natal dispersal: 'Choosing' where to breed from a finite set of available areas. Methods 635 in Ecology and Evolution, 6, 997-1006.

636 Veale, A.J., Clout, M.N. \& Gleeson, D.M. (2011) Genetic population assignment reveals a 637 long-distance incursion to an island by a stoat (Mustela erminea). Biological Invasions, $638 \quad \mathbf{1 4}, 735-742$.

639 Vuilleumier, S. \& Perrin, N. (2006) Effects of cognitive abilities on metapopulation $640 \quad$ connectivity. Oikos, 113, 139-147.

641 Wolfe, M.L., Stoner, D.C., Mecham, C., Mecham, M.B., Durham, S.L., Choate, D.M., ... 
643 Puma Concolor Follow Source-Sink Predictions? Nordic Council for Wildlife

644 Research (NKV).

645 Zalewski, A., Piertney, S.B.S., Zalewska, H. \& Lambin, X. (2009) Landscape barriers reduce 646 gene flow in an invasive carnivore: geographical and local genetic structure of 647 American mink in Scotland. Molecular Ecology, 18, 1601-1615.

648

\section{Supporting Information}

650 Additional supporting information may be found in the online version of this article.

651 Appendix S1. DNA extraction, genotyping and pedigree analyses

652 Appendix S2. R code and dataset for the Bayesian multinomial probit model (Model-1)

653 Table S1. Convergence statistics of the five MCMC chains for each model

654 Fig. S1. Matrix of the accumulative number of settled mink from natal to settlement patch.

655 Fig. S2. Quality $(Q)$ per patch.

656 Fig. S3. Correlations between habitat variables.

657 Fig. S4. Patches coloured as per Q and their centroid of mink captures.

658 Fig. S5. Histogram of distances between patches.

659

660 